\title{
Use of Satellite Remote Sensing Data in the Mapping of Global Landslide Susceptibility
}

\author{
Yang Hong ${ }^{1,2}$, Robert F. Adler ${ }^{2}$, George J.Huffman ${ }^{2,3}$ \\ (Corresponding author E-mail: vanghong@agnes.gsfc.nasa.gov)
}

\author{
${ }^{1}$ Goddard Earth and Science Technology Center, University of Maryland, Baltimore County \\ ${ }^{2}$ NASA/GSFC, Code 613.1, Greenbelt, Maryland 20771; ${ }^{3}$ Science Systems and Applications Inc. \\ (Prepared for Journal of Natural Hazards Special Issue: \\ Use of Satellite Remote Sensing Data in Flood and Landslide Analysis)
}

\section{Popular Summary}

Satellite remote sensing data has significant potential use in analysis of natural hazards such as landslides. Relying on the recent advances in satellite remote sensing and geographic information system (GIS) techniques, this paper aims to map landslide susceptibility over most of the globe using a GIS-based weighted linear combination method. First, six relevant landslide-controlling factors are derived from geospatial remote sensing data and coded into a GIS system. Next, continuous susceptibility values from low to high are assigned to each of the six factors. Second, a continuous scale of a global landslide susceptibility index is derived using GIS weighted linear combination based on each factor's relative significance to the process of landslide occurrence (e.g., slope is the most important factor, soil types and soil texture are also primary-level parameters, while elevation, land cover types, and drainage density are secondary in importance). Finally, the continuous index map is further classified into six susceptibility categories. Results show the hot spots of landslide-prone regions include the Pacific Rim, the Himalayas and South Asia, Rocky Mountains, Appalachian Mountains, Alps, and parts of the Middle East and Africa. India, China, Nepal, Japan, the USA, and Peru are shown to have landslide-prone areas. This first-cut global landslide susceptibility map forms a starting point to provide a global view of landslide risks and may be used in conjunction with satellite-based precipitation information to potentially detect areas with significant landslide potential due to heavy rainfall. 


\title{
Use of Satellite Remote Sensing Data in the Mapping of Global Landslide Susceptibility
}

\author{
Yang Hong ${ }^{1,2 *}$, Robert Adler ${ }^{2}$, George Huffman ${ }^{2,3}$ \\ ${ }^{1}$ Goddard Earth and Science Technology Center, University of Maryland Baltimore County, MD \\ ${ }^{2}$ NASA Goddard Space Flight Center, Laboratory for Atmospheres, Greenbelt, Maryland 20771 \\ ${ }^{3}$ Science System Application Inc., Greenbelt, Maryland 20771
}

Prepared for Journal of Natural Hazards Special Issue:

Use of Satellite Remote Sensing Data in Flood and Landslide Analysis

Deadline: August 15, 2006

*Corresponding Author: Dr. Yang Hong

Mailing: NASA Goddard Space Flight Center, Mail code 613.1, Greenbelt, MD 20771

Phone: 1-301-614-6232; Fax: 1-301-614-5492; Email: yanghong@agnes.gsfc.nasa.gov 


\title{
Use of Satellite Remote Sensing Data in the Mapping of Global Landslide Susceptibility
}

\begin{abstract}
Satellite remote sensing data has significant potential use in analysis of natural hazards such as landslides. Relying on the recent advances in satellite remote sensing and geographic information system (GIS) techniques, this paper aims to map landslide susceptibility over most of the globe using a GIS-based weighted linear combination method. First, six relevant landslide-controlling factors are derived from geospatial remote sensing data and coded into a GIS system. Next, continuous susceptibility values from low to high are assigned to each of the six factors. Second, a continuous scale of a global landslide susceptibility index is derived using GIS weighted linear combination based on each factor's relative significance to the process of landslide occurrence (e.g., slope is the most important factor, soil types and soil texture are also primary-level parameters, while elevation, land cover types, and drainage density are secondary in importance). Finally, the continuous index map is further classified into six susceptibility categories. Results show the hot spots of landslide-prone regions include the Pacific Rim, the Himalayas and South Asia, Rocky Mountains, Appalachian Mountains, Alps, and parts of the Middle East and Africa. India, China, Nepal, Japan, the USA, and Peru are shown to have landslide-prone areas. This first-cut global landslide susceptibility map forms a starting point to provide a global view of landslide risks and may be used in conjunction with satellite-based precipitation information to potentially detect areas with significant landslide potential due to heavy rainfall.
\end{abstract}

Keywords: Satellite remote sensing, Landslide susceptibility, GIS 


\section{Introduction}

Shallow landslides, often called mudslides or debris flows, are rapidly moving flows of mixed rocks and mud that move downhill at speeds of 35 miles per hour or more, kill people and destroy homes, roads, bridges, and other property. They are caused primarily by prolonged, heavy rainfall on saturated hill slopes (Baum et al., 2002). For example, hurricane Mitch caused catastrophic landslides throughout the Caribbean and Central America area in October, 1998. It was reported that 6,600 persons were killed and 8,052 injured. Approximately 1.4 million people were left homeless. More than 92 bridges had been destroyed, and nearly 70 percent of crops were damaged. Although landslide events occur frequently worldwide, unfortunately, no map or guideline currently exists to assess the relative landslide potential throughout the globe. Although it is still difficult to predict a landslide event in space and time, an area may be ranked according to the degree of potential hazard from landslides in order to possibly minimize damage (Saha et al., 2005).

Landslide occurrence depends on complex interactions among a large number of partially interrelated factors. These parameters, according to Dail et al. (2002) can be grouped into two categories: (1) preparatory variables including slope, soil properties, 'elevation, aspect, land cover, lithology etc; and (2) the triggering variables such as heavy rainfall and glacier outburst. A field survey, conventionally, is the most exact method to assess landslide susceptibility (LS). However, analyzing landslide potential that might occur in a large area is very difficult and expensive in terms of time and money. This is especially true in developing countries where expensive ground observation networks are prohibitive and in mountainous areas where access is difficult. In many countries, remote sensing information may be the only possible source available for such studies. Currently 
available satellite data may provide useful and accurate information on earth surface features and dynamic processes involved in landslide occurrence.

This paper takes the opportunity to use high-resolution satellite remote sensing products to attempt a global-scale landslide hazard assessment. Information from remotely sensed data is digitally processed and integrated with other ancillary information using a Geographical Information System (GIS). By using GIS-based map overlay techniques, it is possible to quantitatively combine several layers of different parameters (e.g. elevation, slope, land use, etc.) to produce spatial patterns of LS on a global scale. This first-cut global LS map may form a starting point to provide a global assessment of landslide hazards and could be used in conjunction with satellite-based precipitation information to predict landslides triggered by heavy rainfall over susceptible areas.

The outline of this paper is as follows: landslide-controlling factors and geospatial data sets are described in section 2; development of the global LS map is presented in section 3 , followed by discussion of results in section 4 .

\section{Satellite Remote Sensing and Geospatial Datasets}

\section{1 landslide controlling factors}

Landslide occurrence depends on complex interactions among a large number of factors. Table 1 lists landslide controlling factors: geologic setting, geomorphic feature, soil property, land cover characteristics, and hydrological and human impacts. According to Dai et al. (2002), these factors can also breakdown into two interactive categories: static and dynamic factors. Factors that trigger mass movements are called dynamic 
factors, mainly rainfall and earthquakes. Basic surface-related characteristics that are related to sliding are called static factors or primary factors (Silde and Ochiai, 2006). Static factors are the determinants of landslide susceptibility, and can be derived from surface characteristics.

\subsection{Geospatial data sets}

Remote sensing products can be utilized for deriving various parameters related to landslide controlling factors. Several geospatial data sets were used in this study and their spatial scales arrange from 30 -meter to 0.25 degree grid sizes. Brief descriptions of the data sets are below.

\subsubsection{Digital elevation model data and its derivatives}

The basic digital elevation model (DEM) data set used in this study includes National Aeronautics and Space Administration (NASA) Shuttle Radar Topography Mission (SRTM; http://www2.jpl.nasa.gov/srtm/) dataset. The SRTM data are a major breakthrough in digital mapping of the world (with $30 \mathrm{~m}$ horizontal spatial resolution and vertical error less then $16 \mathrm{~m}$ ), and provides a major advance in the availability of high quality elevation data for large portions of the tropics and other areas of the developing world. SRTM data are distributed in two levels: SRTM1 (for the U.S. and its territories and possessions) with data sampled at one arc-second intervals in latitude and longitude, and SRTM3 $\left(60^{\circ} \mathrm{N}-60^{\circ} \mathrm{S}\right)$ sampled at three arc-seconds. The horizontal resolution of SRTM1 has about 30-meter resolution and SRTM3 has 90-meter resolution in equator areas. A description of the SRTM mission can be found in Farr and Kobrick (2000). 
DEM data can be used to derive topographic factors, other than simply elevation, including slopes, aspects, hill shading, slope curvature, slope roughness, slope area and qualitative classification of landforms (Fernandez et al., 2003). DEM data can be also used to derive hydrological parameters (flow direction, flow path, and basin and river network basin). Figure 1 shows the Puerto Rico 30-meter SRTM DEM map and slopes calculated at various resolutions. Table 2 lists the statistics of their slopes derived from 30-m, 90-m, and 1000-m spatial resolution of DEM over Puerto Rico, respectively.

The United States Geological Survey's GTOPO30 DEM (http://edcdaac.usgs.gov/gtopo30/gtopo30.html), with a 1-km horizontal resolution is used in this study to fill the SRTM gaps. The SRTM data covers all land between 56 degrees south and 60 degrees north latitude, about $80 \%$ of global land.

\subsubsection{Land cover data}

MODIS (Moderate Resolution Imaging Spectroradiometer) is a key instrument aboard the Terra and Aqua satellites. Terra's orbit around the Earth is timed so that it passes from north to south across the equator in the morning, while Aqua passes south to north over the equator in the afternoon. MODIS is viewing the entire Earth's surface every 1 to 2 days, acquiring data in 36 spectral bands, or groups of wavelengths (http://modis.gsfc.nasa.gov/index.php). These data improve our understanding of global dynamics and processes occurring on the land, in the oceans, and in the lower atmosphere. The global land cover data from MODIS are used as a simple surrogate for vegetation and land use types. The MODIS land cover classification map is available at the highest resolution available, 250-meter. This land cover product uses the classification scheme 
proposed by the International Geosphere Biosphere Programme (IGBP). The MODIS land cover products describe the geographic distribution of the 17 IGBP land cover types based on an annual time series of observations (Fridel et al., 2002). For each spatial resolution there is a land cover type classification layer (with numbers from 0 to 17), a classifier confidence assessment layer, and 17 associated layers that provide the percentage, from 0 to 100 , of each land cover type per cell. The data set also provides the fraction of each of the 17 classes within the coarser resolution cells.

\subsubsection{FAO digital soil map}

Information on soil properties is obtained from the Digital Soil of the World published in 2003 by Food and Agriculture Organization (FAO) of the United Nations (http://www.fao.org/AG/agl/agll/dsmw.htm). The soil parameters available include soil type classification, clay mineralogy, soil depth, soil moisture capacity, soil bulk density, soil compaction, etc. This product is not based on satellite information directly, but is based primarily on ground surveys and national databases.

\subsubsection{Soil characteristics}

A second non-satellite database is the International Satellite Land Surface Climatology Project (ISLSCP) Initiative II Data Collection (http://www.gewex.org/islscp.html), which provides gridded data of 18 selected soil parameters. Theses data sets are distributed by the Oak Ridge National Laboratory Distributed Active Archive Center (http://daac.ornl.gov/) at quarter degree resolution. One important parameter for this study is the soil texture. Following the U.S. Department of Agriculture soil texture classification, the 13 textural classes reflect the relative proportions of clay (granules size less than $0.002 \mathrm{~mm})$, silt $(0.002-0.05 \mathrm{~mm})$ and sand 
$(0.05-2 \mathrm{~mm})$ in the soil. Three textural categories are recognized among the 13 original texture classes: coarse (1): sands, loamy sands and sandy loams with less than 18 percent clay and more than 65 percent sand; medium (2): sandy loams, loams, sandy clay loams, silt loams, silt, silty clay loams and clay loams with less than 35 percent clay and less than 65 percent sand (the sand fraction may be as high as 82 percent if a minimum of 18 percent clay is present); and fine (3): clay, silty clays, sandy clays, clay loams, with more than 35 percent clay. Note that these soil texture classes are interpolated to the highest DEM spatial scale.

\section{Development of the global landslide susceptibility map}

Landslide susceptibility can be mapped out using various methods depending on the data availability (Guzzentti et al., 1999). However, is it possible for a landslide. susceptibility map to be produced with limited data? Fabbri et al. (2003) and Coe et al. (2004) suggest that this is not only possible, but more accurate. More information does not necessary lead to better results, depending on the quality of the data. Coe et al. (2004) evaluated the effectiveness of a landslide susceptibility map derived from four topographic parameters (elevation, slope angle, curvature, and aspect) and found two of these, a combination of elevation and slope angle, best portrayed landslide susceptibility. Similarly, Fabbri et al. (2003) found three data layers (slope, elevation, and aspect) derived exclusively from a DEM provided better results than six data layers (including other geology, surficial materials, and land use). These results seemingly indicate that topography was the dominant control in determining location of landslide occurrence. 
The statements below describe the landslide susceptibility mapping process used in this study:

1) classifying landslide-controlling factors into nominal categories with a continuum of increasing susceptibility to shallow landslides;

2) assigning susceptibility values from zero to one for each factors; and

3) mapping the landslide susceptibility using weighted linear combination methods.

\subsection{Assignment of numerical values for landslide-controlling factors}

Based on the aforementioned geospatial data sets, a number of landslidecontrolling parameters are derived, including elevation, slope, aspect, curvature, concavity, percentage of soil types (including clay, foam, silt, and sand etc.), soil texture, land use classification, and hydrological variables (drainage density, flow accumulation, and flow path). All parameters have been downscaled or interpolated to the SRTM elemental horizontal scale of 30-meter. Due to the lack of global landslide occurrence data, landslide -factor selection and assignment of numerical values are based on the referenced studies and on information availability. Among these factors, previous studies (Dai et al., 2002; Carara et al., 1991; Anbalagan et al., 1992; Larsen and Torres Sanchez, 1998; Lee and Min, 2001; Saha et al., 2002; Fabbri et al., 2003; Sarkar and Kanungo, 2004; Coe et al., 2004) demonstrated that six parameters, slope, type of soil (clay, soam, percentage of clay), soil texture, elevation, MODIS land cover, and drainage density, are closely associated with landslide occurrences.

The first step is to classify each landslide-controlling factor into various categories. For example, using an approach published by Larsen and Torres-Sanchez 
(1998), land cover can be discretized into several general categories: (a) forested land; (b) shrub land; (c) grass land; (d) pasture and/or cropland, and (e) developed land and/or road corridors. These land use/land cover categories describe a continuum of increasing susceptibility to shallow landslides. In this study, following the same approach, the 17 MODIS land cover types are classified into 11 categories (Table 3), which describe increasing landslide susceptibility to shallow landslides. Therefore, landslide susceptibility values from zero to one are assigned to each category, respectively. The effect of slope, soil type, and soil texture on landslides was widely documented by Dai et al. (2002) and Lee and Min (2001). In many regions, elevation according to Coe et al. (2004) is approximately a proxy for mean rainfall that increases with height due to orographic effects and high elevation areas are preferentially susceptible to landslides because they receive greater amounts of rainfall than areas at lower elevations. Drainage density provides an indirect measure of groundwater conditions, which have an important role to play in landslide activity (Sarkar and Kanungo, 2004). Sarkar and Kanungo (2004) also found an inverse relationship between landslides and drainage density which may be due to high infiltration in weathered gneisses causing more instability in the area. Based on these previous studies, assignment of landslide susceptibility values for other parameters is based on several empirical assumptions: (1) higher slope, higher susceptibility; (2) coarser and looser soil, higher susceptibility; (3) higher elevation, higher susceptibility, and (4) decreasing susceptibility for larger drainage density. Under assumption (1), for example, the slope map units are given zero susceptibility value for class of flat slopes and susceptibility value one is assigned to the class of steepest slopes. 
Thus, numerical values $x_{k}(i, j, t)$ of parameter $\mathrm{k}$ are normalized from zero to one, as shown in Equation 1:

$$
y_{k}(i, j, t)=\frac{x_{k}(i, j, t)-x_{k}^{\min }}{x_{k}^{\max }-x_{k}^{\min }}
$$

where $x_{k}(i, j, t)$ is the original numerical value of $\mathrm{k}^{\text {th }}$ factor at pixel location $(\mathrm{i}, \mathrm{j})$ at time $\mathrm{t}$ and $y_{k}(i, j, t)$ is the numerical value normalized from $x_{k}(i, j, t)$. Where $x_{k}^{\max }$ $\left(x_{k}^{\min }\right)$ is the upper (lower) numerical value limit of $\mathrm{k}^{\text {th }}$ factor. As pointed out above, these landslide-controlling factors are semi-static so that the time $t$ only represents the sampling time of these geospatial data sets. Final landslide susceptibility values are combined results of the numerical values assigned to each of the landslide-controlling parameters.

\subsection{Weighted Linear Combination}

To represent and interactively examine these factors, a series of thematic maps have been created, using the GIS overlay concept of weighted linear combination (WLC). WLC is a method where landslide-controlling factors can be combined by applying primary- and second-level weights (Ayalew et al., 2004). In this study, the weighted linear combination method is performed to derive the final susceptibility values, as shown in Equation 2.

$$
Z(i, j, t)=\sum_{k=1}^{n} w_{k} y_{k}(i, j, t), \text { where } \sum_{k=1}^{n} w_{k}=1
$$

$Z(i, j, t)$ is final susceptibility value for pixel $(i, j)$ and $w_{k}$ is the linear combination weight for $k^{\text {th }}$ factor, where $k=1-6$ in this study. Next step is to determine the weight for each parameter. 
Both Coe et al. (2004) and Fabbri et al. (2003) found that topography was the dominant control in determining location of landslide occurrences. Dai et al. (2002) and Lee and Min (2001) reported slope steepness has the most influence on shallow landslide likelihood, followed by soil texture and soil types that mantles the slope. The other parameters, land covers (Larsen and Torres-Sanchez, 1998), elevation (Coe et al., 2004), and drainage density (Sarkar and Kanungo, 2004), also play important but secondary roles in determining landslide potentials. Following these analysis, among the six parameters, we find that the slope is the most important factor and soil types and soil texture are also primary-level parameters, while the elevation, land cover types, and drainage density are of secondary-level importance. Several WLC susceptibility models were tried reflecting different weights combinations. Results were inter-compared with existing regional susceptibility maps (http://landslides.usgs.gov) and Figure 2. The best model obtained was the one with weight determination $(0.3,0.2,0.2,0.1,0.1$, and 0.1$)$ for the six parameters (slope, type of soil, soil texture, elevation, MODIS land cover type, and drainage density), respectively. The consequent range in susceptibility values is normalized from zero to one. The larger the susceptibility value, numerically, the greater the potential to produce landslide.

\subsection{The Global Landslide Susceptibility Map}

This continuous scale of numerical indices of landslide susceptibility can be further classified into several categories (Sarkar and Kanungo, 2004). A judicious way for such classification is to search the category boundaries at abrupt changes in histogram of the landslide susceptibility values (Davis, 1986). As shown in Figure 2-3, the global 
landslide susceptibility index is divided into six categories of landslide susceptibility: -1water bodies; 0 -permanent snow or ice; 1-very low; 2-low; 3-moderate; 4-high; 5-very high susceptibility. One can see that the North America landslide susceptibility map produced from this approach (Figure 2d) captures most of the landslide-prone areas according to USGS North American study (Figure 2e-f). Figure 2 (d-f) shows that landslides can occur in all of the contiguous 48 states, but more often in the coastal and mountainous areas of California, Oregon, and Washington, as well as Rocky Mountain states, and mountainous and hilly regions of the East.

The resulting global LS map (Figure 3a) demonstrates the hot spots of the high landslide potential regions: the Pacific Rim, the Alps, the Himalayas and South Asia, Rocky Mountains, Appalachian Mountains, and parts of the Middle East and Africa. India, China, Nepal, Japan, the USA, and Peru are shown to be landslide-prone countries. These results are similar to those reported by Sidle and Ochiai (2006). Figure 3b-c also shows the percentage of five categories. The categories of very high and high susceptibility account for $3.2 \%$ and $14.6 \%$ out of global land areas (Table 4), respectively. These two categories are dominated by areas with steep slopes, high elevations, high concentration of clay, and fine soil texture. Excluding the permanent snow and ice over land, the very high susceptibility category (Category 5) accounts for approximately 5\%of the land area (Table 4, row 6). The majority of the land is placed into the moderate or low landslide-prone categories.

\section{Conclusion and Discussion}

A major outcome of this work is the development of a global view of landslide susceptibility, only possible because of the utilization of satellite products. By using GIS- 
based map overlay techniques, the derived landslide susceptibility values are the weighted linear summation of the slope, soil type, soil texture, elevation, vegetation cover, and drainage density. The global LS map will provide guidelines to assess the spatial distribution of potential landslides by identifying landslide-prone areas. For example, areas identified as "high potential for landslides" could be scrutinized more thoroughly from the ground than would those with "low potential". Improved susceptibility information would be available for these candidate areas after a site inspection. This landslide susceptibility information should provide a useful new tool for study and evaluation of landslide occurrence.

The LS map provides a starting point to give a global view of landslide hazard information by combining with satellite-based, real-time rainfall measuring system. (http://trmm.gsfc.nasa.gov) to monitor when areas with significant landslide potential receive heavy rainfall which might initiate landslides in those susceptible areas. For example, an empirical landslide-triggering rainfall intensity-duration threshold can be calibrated using the TRMM-based Multi-satellite Precipitation Analysis (TMPA) (Huffman et al., 2006) with the global landslide susceptibility map. This rainfall calibration could be done globally (Caine 1980; Figure 4a) or for major climatologic regions (Larsen and Simon, 1993; Godt et al. 2004). Figure 4b shows a satellite rainfall example associated with the recent landslide triggered by heavy rainfall on the Philippine Island of Leyte on Feb 17, 2006, with at least 1800 reported deaths. Therefore, the landslide hazard $(\mathrm{H})$ can be expressed as a function of landslide susceptibility $(\mathrm{z})$ and the rainfall intensity-duration (I-D) at continuously over a time-space domain (Equation 3). 
The location and timing of any threshold exceedence can then be identified and compared to reports of actual occurrences.

$$
H(i, j, t)=f(z(i, j, t), \quad I(i, j, t), \quad D(i, j, t))
$$

The quality of the LS map obtained, will rely heavily on accuracy and scale of information derived from the geospatial data. The first-cut global landslide susceptibility map produced here needs validation from local inventory data and we believe that the iterative verification processes can correct and enhance this map with many existing local inventory datasets. The LS map can be updated whenever new or better geospatial datasets become available. The LS map can also behave semi-dynamically by routinely updating it from information of monthly land cover change and/or antecedent precipitation conditions. The procedure can be systematic and applicable over the globe: In addition, more information (e.g. lithology) could be incorporated into this LS map in a general or site-specific fashion as they become available. Additionally, soil moisture conditions from NASA Aqua AMSR-E and TRMM will be examined for usefulness in a planned quasi-global landslide prediction system. We expect that the accuracy of such susceptibility maps will increase in time.

\section{Acknowledgement:}

This research is supported by NASA's Applied Sciences program under Steven Ambrose of NASA Headquarters. 


\section{Reference}

Anbalagan, R., 1992, Landslide hazard evaluation and zonation mapping in mountainous terrain. Engineering Geology 32: 269-277

Ayalew, L., H. Yamagishi, and N. Ugawa, 2004: Landslide susceptibility mapping using GIS-based weighted linear combination, the case in Tsugawa area of Agano River, Niigata Prefecure, Japan, Landslide 1:73-81

Baum, R. L., W. Z. Savage, and J. W Godt, 2002: TRIGRS - A Fortran program for transient rainfall infiltration and grid-based regional slope-stability analysis: U. S. Geological Survey Open-File Report 02-0424, 64 p. http://pubs.usgs.gov/of/2002/ofr-02-424.

Caine, N., 1980: The rainfall intensity-duration control of shallow landslides and debris flows: Geografiska Annaler, v. 62A, p. 23-27.

Canuti, P., P. Focardi, and C.A. Garzonio, 1985, Correlation between rainfall and landslide, Bull. Int. Assoc. Eng. Geol., 32, 49-54

Carrara, A., M. Cardinali, R. Detti, F. Guzzetti, V. Pasqui, and P. Reichenbach, 1991, GIS techniques and statistical models in evaluating landslide hazard. Earth Surface Processes and Landforms, 16, 427- 445

Coe, J. A., J. W. Godt, R. L. Baum, R. C. Bucknam, and J.A. Michael, 2004: Landslide susceptibility from topography in Guatemala, in, Lacerda and others (eds.), Landslides: Evaluation and Stabilization: London, Taylor and Francis Group, p69-78.

Dai, F.C., Lee CF (2002) Landslide characteristics and slope instability modeling using GIS, Lantau Island, Hong Kong, Geomorphology 42:213-238 
Davis, J. C., 1986. Statistics and Data Analysis in Geology, John Wiley \& Sons, New York, N.Y., 646p

Fabbri, A. G., C.F. Chung, A. Cendrero, and J. Remondo, 2003; Is prediction of future landslides possible with GIS? Journal of Natural Hazards 30: 487-499

Farr, T., and M. Kobrick (2000), Shuttle Radar Topography Mission produces a wealth of data, Eos Trans. AGU, 81, 583-585

Fernandez, T., C. Irigaray, R. El Hamdouni, and J. Chacon, 2003: Methodology for Landslide Susceptibility Mapping by Means of a GIS, Application to the Contraviesa Area (Granada, Spain), Journal of Natural Hazards, 30, 297-308

Friedl., M.A. , D.K. McIver, J.C.F. Hodges, X.Y. Zhang, D. Muchoney, A.H. Strahler, C.E. Woodcock, S. Gopal, A. Schneider, A. Cooper, A. Baccini, F. Gao, and C. Schaaf, Global Land Cover Mapping from MODIS: Algorithms and Early Results, Remote Sensing of Environment 83(1-2):287-302.

Godt, J., 2004: Observed and Modeled conditions for shallow landslide in the Seattle, Washington area. Ph.D dissertation, University, of Colorado, Boulder, CO.

Guzzetti, F., A. Carrara, M. Cardinali, P. Reichenbach (1999): Landslide hazard evaluation: a review of current techniques and their application in a multi-scale study, Central Italy. Geomorphology 31:181-216

Huffman, G.J., R.F. Adler, D.T. Bolvin, G. Gu, E.J. Nelkin, K.P. Bowman, Y. Hong, E.F. Stocker, D.B. Wolff, 2006: The TRMM Multi-satellite Precipitation Analysis: Quasi-Global, Multi-Year, Combined-Sensor Precipitation Estimates at Fine Scale. J. Hydrometeor., accepted 
Larsen, M. C., and A. Simon, 1993: A rainfall intensity-duration threshold for landslides in a humid-tropical environment, Puerto Rico: Geografiska Annaler, v. 75A, p1323

Larsen, M.C., and A. J. Torres Sanchez, 1998: The frequency and distribution of recent landslides in three montane tropical regions of Puerto Rico: Geomorphology, v. 24, p. 309-331.

Lee, S., K. Min (2001) Statistical analysis of landslide susceptibility at Yongin, Korea, Environ Geol 40:1095-1113

Sarkar, S., D. P. Kanungo (2004): An integrated approach for landslide susceptibility mapping using remote sensing and GIS. Photo Eng Remote Sens 70:617-625

Saha, A. K., R.P. Gupta, and M.K. Arora, 2002: GIS-based landslide hazard zonation in the Bagirathi (Ganga) Valley, Himalayas, International Journal of Remote Sensing, 23, no.2, 357-369. 2002

Saha, A. K., R. P. Gupta, I. Sarkar, M. K. Arora, E. Csaplovics, 2005: An approach for GIS-based statistical landslide susceptibility zonation —with a case study in the Himalayas, Landslides, 2:61-69

Sidle, R.C. and H. Ochiai, Landslide Processes, Prediction, and Land use, Washington DC, American Geophysical Union, pp1-312, 20 
Table 1 landslide controlling factors

\begin{tabular}{|c|c|c|}
\hline Category & Controlling factors & Availability \\
\hline Geology & $\begin{array}{l}\text { Lithological makeup, rock units (mudstone, sandstone, } \\
\text { limestone and greentuffes), tectonics, bedrock structure }\end{array}$ & Local \\
\hline Geomorphology & $\begin{array}{l}\text { Elevation, Slope, slope shape, aspect, curvature, } \\
\text { concavity }\end{array}$ & Global \\
\hline Soil & $\begin{array}{l}\text { Soil types (clay, silt, foam, sand...), soil texture, soil } \\
\text { depth, }\end{array}$ & Global \\
\hline Land cover & Vegetated, barren, built-up, developed, shrub, grass... & Global \\
\hline Hydrology & $\begin{array}{l}\text { Rainfall, Soil moisture, snowmelt, drainage density or } \\
\text { flow accumulation, flow direction(sliding path), } \\
\text { infiltration }\end{array}$ & Global \\
\hline Human impact & $\begin{array}{l}\text { Urban build-up, road construction, deforestation } \\
\text { (burning), irrigation, mining, artificial vibration.... }\end{array}$ & Regional \\
\hline
\end{tabular}


Table 2 the statistics of slopes derived from different resolution DEM over Puerto Rico

\begin{tabular}{|c|c|c|c|c|c|c|}
\hline & \multicolumn{4}{|c|}{ Slope property(degree) } & \multirow[b]{2}{*}{ Number of pixels } \\
\hline & & $\operatorname{Max}$ & Mean & Median & Standard deviation & \\
\hline \multirow[t]{3}{*}{$\mathrm{DEM}$} & $30-\mathrm{m}$ & 89.95 & 13.45 & 11.31 & 12.41 & 11947162 \\
\hline & $90-\mathrm{m}$ & 73 & 13.48 & 12.16 & 11.8 & 1322659 \\
\hline & $1000-\mathrm{m}$ & 58 & 13.15 & 12.12 & 11.42 & 11029 \\
\hline
\end{tabular}


Table 3 Assignment of numerical values of landslide susceptibility for different land cover types

\begin{tabular}{|l|l|l|l|}
\hline \hline CATEGORY & $\begin{array}{l}\text { ASSIGNMENT OF } \\
\text { SUSCEPTIBILITY }\end{array}$ & $\begin{array}{l}\text { ORIGIONAL MODIS } \\
\text { CLASSES }\end{array}$ & CONTENTS \\
\hline 0 & 0 & 0,15 & Water bodies; permanent snow and ice \\
\hline 1 & 0.1 & $11,1,2$ & Evergreen Forests, permanent wetland \\
\hline 2 & 0.2 & 3,4 & Deciduous Forests or mixed forested lands \\
\hline 3 & 0.3 & 5 & Mixed forests \\
\hline 4 & 0.4 & 6,7 & Open or closed Shrub lands \\
\hline 5 & 0.5 & 8,9 & Woody Savannas or Savannas \\
\hline 6 & 0.6 & 10 & Grass land \\
\hline 7 & 0.7 & 12 & Croplands \\
\hline 8 & 0.8 & 14 & Cropland and/or Natural Vegetation Mosaic \\
\hline 9 & 0.9 & 16 & Barren or Sparsely Vegetated land \\
\hline 10 & 1.0 & 13,17 & Developed land, road corridors, coastal area \\
\hline
\end{tabular}


Table 4 Distribution of Landslide Susceptibility Map

\begin{tabular}{|lllllllll|}
\hline Category & $\mathbf{- 1}$ & $\mathbf{0}$ & $\mathbf{1}$ & $\mathbf{2}$ & $\mathbf{3}$ & $\mathbf{4}$ & $\mathbf{5}$ \\
\hline Susceptibility & Water & snow/ice & Very low & Low & Moderate & high & Very high \\
& & & & & & & & \\
\hline Numerical & -1 & 0 & $0 \sim 0.18$ & $0.19 \sim 0.29$ & $0.3 \sim 0.4$ & $0.4 \sim 0.55$ & $>=0.55$ \\
Values & & & & & & & & \\
\hline (globe) & 66.42 & 11.53 & 3.31 & 5.51 & 6.62 & 5.51 & 1.10 \\
\hline \%(land) & N/A & 34.35 & 8.84 & 18.33 & 20.69 & 14.60 & 3.19 \\
\hline \%(land) & N/A & N/A & 13.46 & 27.90 & 31.51 & 22.22 & 4.86 \\
\hline
\end{tabular}




\section{Figure Captions}

Figure 1. Slope derived from NASA Shuttle Radar Topography Mission data over Puerto Rico. Top Panel-Slope derived from 30-, 90-, and 1000-meter DEM; Bottom panelhistogram of slope distribution.

Figure 2. North America geospatial data such as (a) DEM; (b) slope; (c) MODIS land cover classification, (d) landslide susceptibility indices derived from this study, and (e-f) landslide susceptibility map from USGS. All rescaled to $1 \mathrm{~km}$ for display purpose.

Figure 3. (a) Global landslide susceptibility map derived from surface multi-geospatial data; (b) histogram of global landslide susceptibility at continuous numerical values from zero to one; (c) histogram of global landslide susceptibility classified into 6 categories.

Figure 4. (a) An empirical antecedent precipitation accumulation threshold derived from Caine 1980; (b) the rainfall accumulation observed from NASA TRMM multi-satellite precipitation for Philippine landslide event on Feb 17, 2006. Star indicates the timing of landslide occurrence. 


\section{figures}

.Click here to download colour figure: NHAZ_SI_Hongetal_20060814_ppt.ppt

30-M: Max Slope=89 (degree)

90-M: Max Slope=73 (degree)
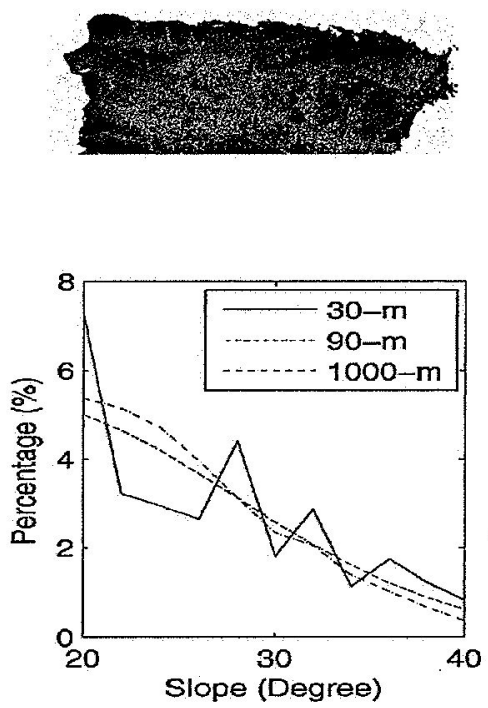

1-KM:Max Slope=58 (Degree)
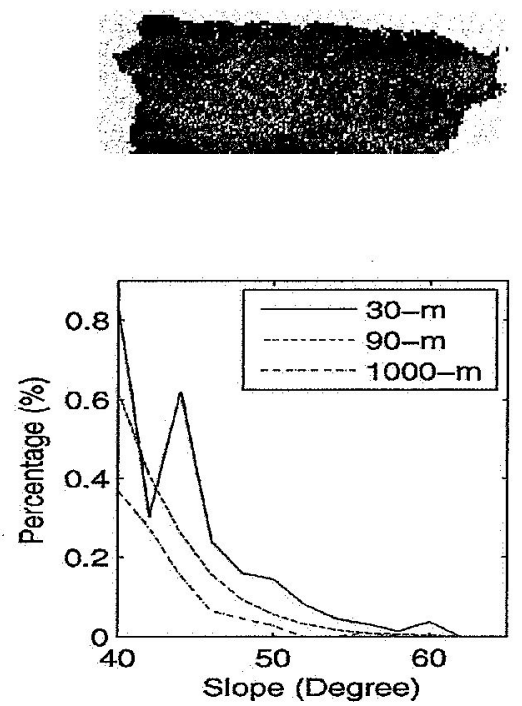

Figure 1. Slope derived from NASA Shuttle Radar Topography Mission data over Puerto Rico. Top Panel-Slope derived from 30-, 90-, and 1000meter DEM; Bottom panel-histogram of slope distribution. 
(a)

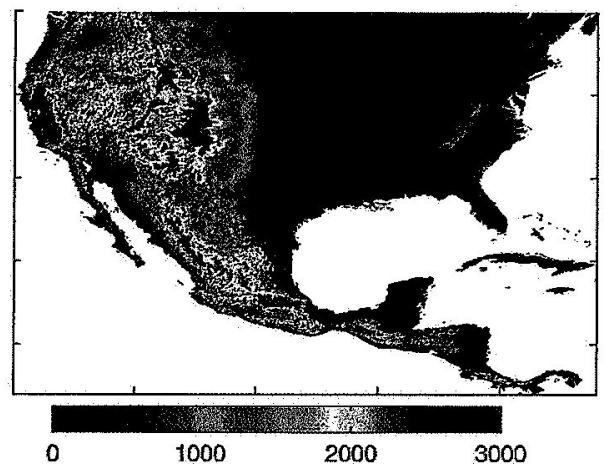

(c)

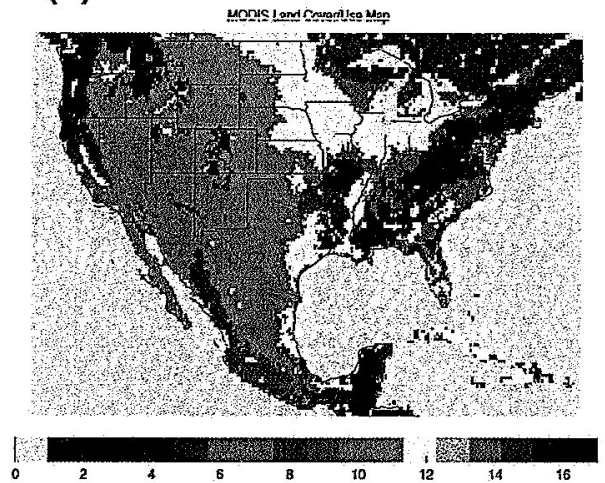

(e)

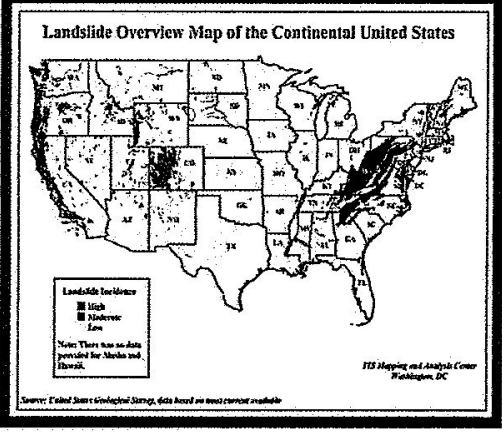

(b)

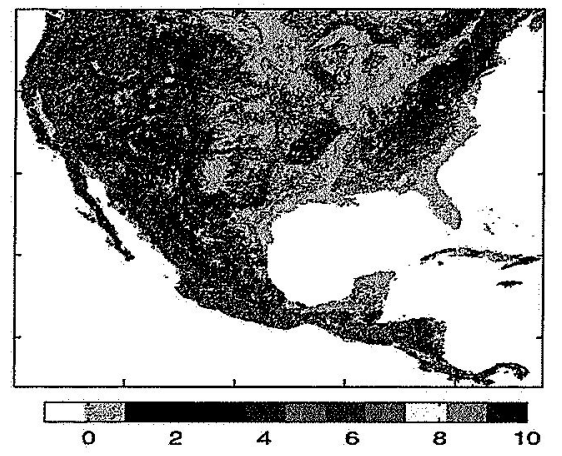

(d)

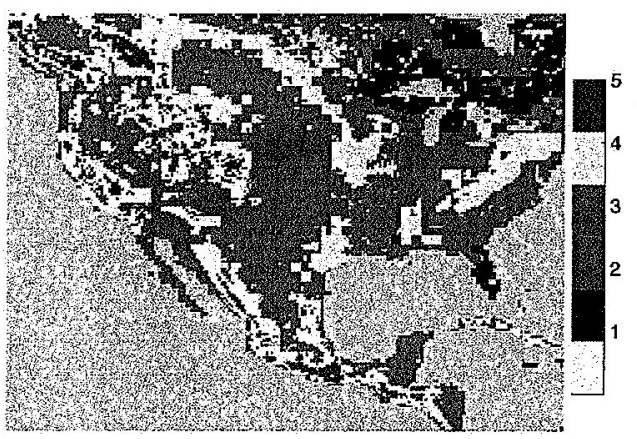

(f)

지어오

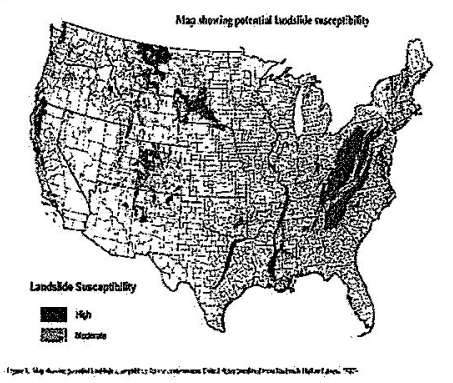

Figure 2. North America geospatial data such as (a) DEM; (b) slope; (c) MODIS land cover classification, (d) landslide susceptibility indices derived from this study, and (e-f) landslide susceptibility map from USGS. All rescaled to $1 \mathrm{~km}$ for display purpose. 
(a)

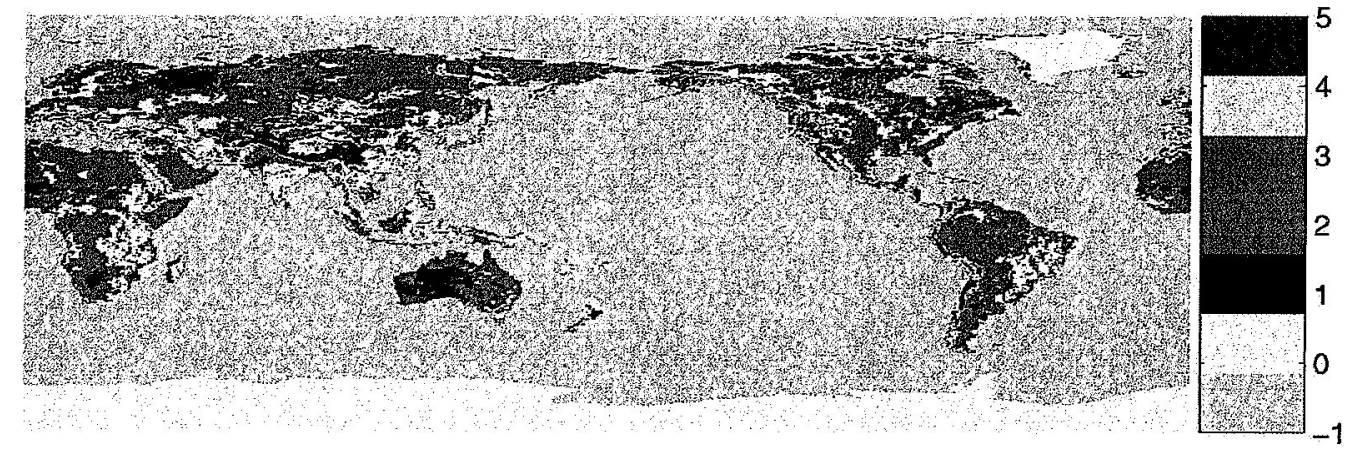

(c)

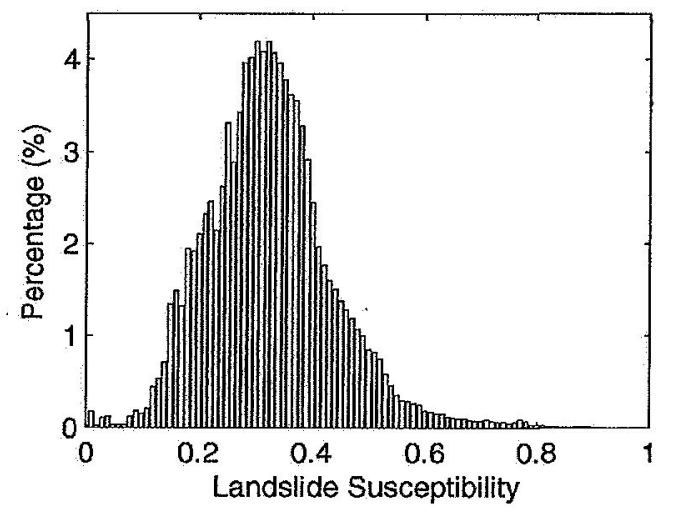

(d)

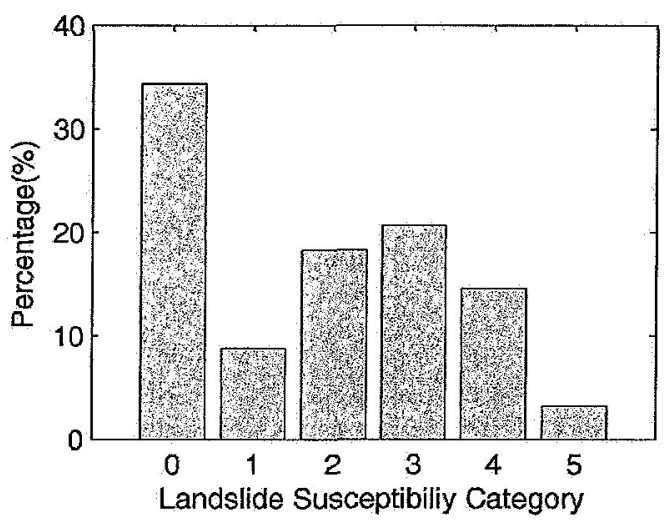

Landslide Susceptibility Category

-1: Water Bodies;

0: Permanent Snow/Ice;

1: Very Low Susceptibility;

2: Low Susceptibility;

3: Moderate Susceptibility;

4: High Susceptibility;

5: Very High Susceptibility.

Figure 3. (a) Global landslide susceptibility map derived from surface multigeospatial data; (b) histogram of global landslide susceptibility at continuous numerical values from zero to one; (c) histogram of global landslide susceptibility classified into 6 categories. 
(a)

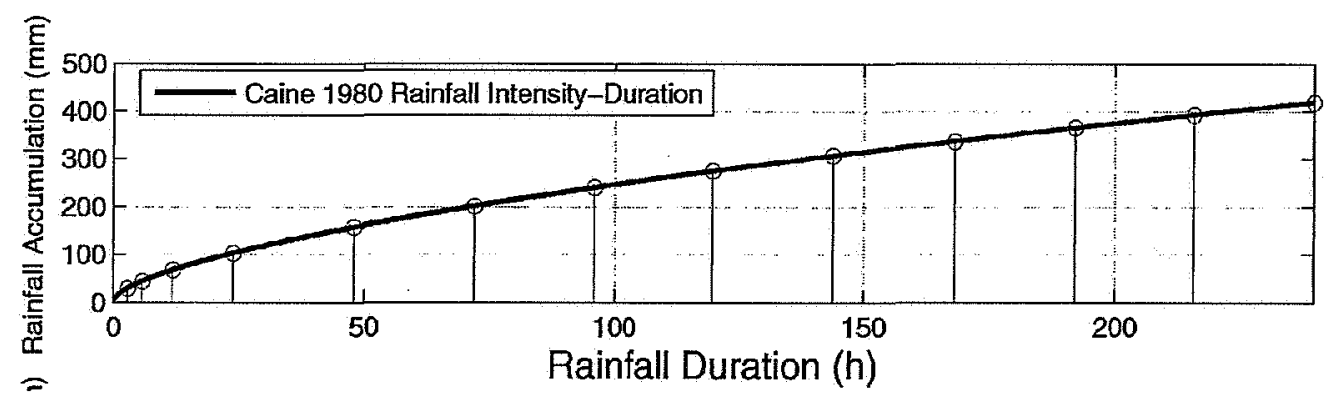

(b)

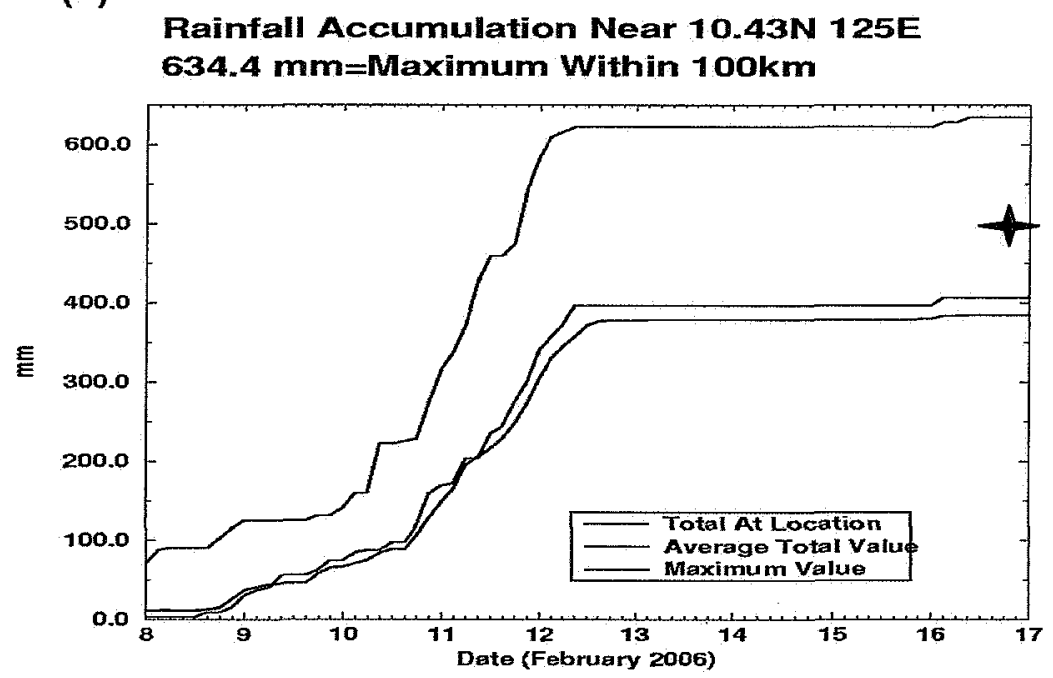

Figure 4. (a) An empirical antecedent precipitation accumulation threshold derived from Caine 1980; (b) the rainfall accumulation observed from NASA TRMM multi-satellite precipitation for Philippine landslide event on Feb 17, 2006. Star indicates the timing of landslide occurrence. 